\title{
Monitoring, trait anxiety, and panic disorder symptomatology in normal subjects
}

Citation for published version (APA):

Muris, P. E. H. M., Merckelbach, H. L. G. J., \& Rassin, E. G. C. (2000). Monitoring, trait anxiety, and panic disorder symptomatology in normal subjects. Journal of Behavior Therapy and Experimental Psychiatry, 31(1), 21-28. https://doi.org/10.1016/S0005-7916(00)00005-7

Document status and date:

Published: 01/01/2000

DOI:

10.1016/S0005-7916(00)00005-7

Document Version:

Publisher's PDF, also known as Version of record

\section{Please check the document version of this publication:}

- A submitted manuscript is the version of the article upon submission and before peer-review. There can be important differences between the submitted version and the official published version of record.

People interested in the research are advised to contact the author for the final version of the publication, or visit the DOI to the publisher's website.

- The final author version and the galley proof are versions of the publication after peer review.

- The final published version features the final layout of the paper including the volume, issue and page numbers.

Link to publication

\footnotetext{
General rights rights.

- You may freely distribute the URL identifying the publication in the public portal. please follow below link for the End User Agreement:

www.umlib.nl/taverne-license

Take down policy

If you believe that this document breaches copyright please contact us at:

repository@maastrichtuniversity.nl

providing details and we will investigate your claim.
}

Copyright and moral rights for the publications made accessible in the public portal are retained by the authors and/or other copyright owners and it is a condition of accessing publications that users recognise and abide by the legal requirements associated with these

- Users may download and print one copy of any publication from the public portal for the purpose of private study or research.

- You may not further distribute the material or use it for any profit-making activity or commercial gain

If the publication is distributed under the terms of Article $25 \mathrm{fa}$ of the Dutch Copyright Act, indicated by the "Taverne" license above, 


\title{
Monitoring, trait anxiety, and panic disorder symptomatology in normal subjects
}

\author{
Peter Muris ${ }^{\mathrm{a}, *}$, Harald Merckelbach ${ }^{\mathrm{b}}$, Eric Rassin ${ }^{\mathrm{b}}$ \\ ${ }^{a}$ Department of Medical, Clinical, and Experimental Psychology, Maastricht University, P.O. Box 616, \\ 6200 MD Maastricht, The Netherlands \\ ${ }^{\mathrm{b}}$ Department of Psychology, Maastricht University, P.O. Box 616, 6200 MD Maastricht, The Netherlands
}

Received 21 April 1999; received in revised form 2 March 2000; accepted 30 March 2000

\begin{abstract}
The present study investigated the relationship between a monitoring coping style and panic disorder symptoms in a normal sample $(N=77)$. The current study found some positive associations between monitoring, on the one hand, and fear of bodily sensations and agoraphobic avoidance, on the other hand. However, the observed correlations between monitoring and panic disorder symptoms were rather small. Moreover, monitoring was not found to be associated with the catastrophic misinterpretation of bodily sensations. As such misinterpretations are thought to play a crucial role in the etiology of panic disorder, the present findings do not support the idea that a monitoring coping style represents a risk factor for panic disorder. (C) 2000 Elsevier Science Ltd. All rights reserved.
\end{abstract}

Keywords: Monitoring; Panic disorder; Cognitive theory of panic; Normal subjects

\section{Introduction}

Panic attacks refer to discrete and unexpected periods of intense fears that are characterized by such symptoms as shortness of breath, palpitations, dizziness, and fear of dying, going crazy or losing control. When panic attacks occur on a regular basis and over a prolonged period, the diagnosis of panic disorder is implicated. Panic

\footnotetext{
"Manuscript published under editorship of former editor L. Reyna.

* Corresponding author. Tel.: + 31-43-3881264; fax: + 31-43-3884155.

E-mail address: p.muris@dep.unimaas.nl (P. Muris).
} 
disorder is often complicated by agoraphobia, i.e., the phobic avoidance of public places or situations in which escape might be difficult when a panic attack occurs (American Psychiatric Association, 1994). According to the cognitive theory of Clark (1986), panic disorder arises as a consequence of catastrophic misinterpretations of bodily sensations. By this view, panic-prone individuals are hypervigilant to bodily sensations and overvalue their significance. As a consequence, these individuals become anxious which further intensifies bodily sensations of arousal. Accordingly, they become trapped in an ever-increasing spiral of bodily sensations, catastrophic misinterpretations, and anxiety which ultimately may result in a panic attack. While a number of details remain unresolved, there is now a large body of evidence indicating that the cognitive theory offers a fruitful conceptualization of the etiology of panic disorder (see, for a critical review, McNally, 1994).

Monitoring refers to the extent to which an individual scans for or attends to threatening information. It is thought to represent an important index of individual differences in response to aversive stimuli or situations (see Miller, Combs \& Kruus, 1993; Muris, 1994). Various studies have examined whether monitoring plays a role in how people cope with threatening life events. In general, these studies found that high monitors (i.e., individuals with a high monitoring style) display more distress and dysfunction, both physically and psychologically, than low monitors (i.e., individuals with a low monitoring style). For example, Miller and Mangan (1983) found in their sample of women who had to undergo a colposcopy, that high monitors were more anxious during anticipation, exhibited more muscular tension in the vaginal area during the examination itself, and reported more pain and discomfort on the five days following the procedure compared to low monitors.

In an attempt to explain the disruptive effects of monitoring, Miller (e.g., Miller, Roussi, Caputo \& Kruus, 1995; Schwartz, Lerman, Miller, Daly \& Masny, 1995) formulated the Monitoring Process Model. According to this model, high and low monitors differ in their encoding of threatening situations. That is, when confronted with threat, high but not low monitors are more inclined to scan for internal and external threat cues. As a result, these cues become hyperaccessible. This process generates a high degree of intrusive ideation. In addition, high monitors tend to interpret neutral or ambiguous information as highly threatening and ruminate about this information, which, in turn, leads to exaggerated perceptions of personal risk. The high degree of intrusive ideation and perceived risk eventually results in heightened levels of anxiety and distress (see also Muris, De Jongh, Van Zuuren \& Schoenmakers, 1996).

Note that the Monitoring Process Model bears some resemblance to the cognitive theory of panic. Not surprisingly, some authors have proposed that monitoring might be involved in the origins of panic disorder. In Miller's (1992) words: 'It is possible that monitors may be at risk for this disorder, since they appear to attend more intently to their physical symptoms and are more inclined to exaggerate their significance' (p. 262). So far, only one study has directly addressed this issue. In that study, Baptista, Figueira, Lima and Matos (1990) examined interpretative bias phenomena in panic disorder patients and healthy control subjects. Results showed that panic disorder patients interpret ambiguous situations as more threatening than control subjects. 
Furthermore, panic disorder patients were found to give higher probability estimates to unpleasant events and to attribute more negative consequences to these events, especially when physiological arousal (e.g., cardiac acceleration) was involved. While monitoring appeared to be positively associated with the overprediction of threat, this association was restricted to those unpleasant events that were not related to physiological arousal. Thus, the Baptista et al. (1990) study found only partial support for the idea that monitoring is involved in the development of panic disorder.

Trait anxiety is another psychological concept that seems to be closely linked to monitoring. According to Eysenck (1992), high trait anxious individuals are characterized by hypervigilance, that is, an increased attention for threat-related stimuli. Note that hypervigilance is thought to be an important concomitant of the monitoring coping style (cf. supra; Krohne, 1993). Yet, despite this similarity, studies have consistently failed to obtain significant correlations between monitoring and trait anxiety (e.g., Miller \& Mangan, 1983). While the precise role of monitoring in the etiology of pathological anxiety awaits clarification, trait anxiety is generally considered to be a vulnerability factor for anxiety symptoms including panic disorder (e.g., Eysenck, 1992; Rachman, 1998).

The current study sought to explore the relationship between monitoring and panic disorder symptomatology in a normal sample. Seventy-seven female undergraduate students completed the Miller Behavioral Style Scale (MBSS; Miller, 1987), an instrument that intends to measure monitoring coping style, and several panic-related scales. Subjects also completed the trait anxiety scale of the Spielberger State-Trait Anxiety Inventory (STAI-trait; Spielberger, 1983). The major aim of the study was to investigate the hypothesis that monitoring is substantially related to panic disorder symptoms even when controlling for levels of trait anxiety. More specifically, it was tested whether monitoring is, indeed, positively associated with fear of bodily cues, catastrophic misinterpretation of such sensations, and agoraphobic symptoms.

\section{Method}

Subjects were 77 female undergraduate psychology students. They volunteered to complete some questionnaires (see below) in return for a small financial compensation. Their mean age was 19 years (range 17-25).

Monitoring was assessed with the MBSS. This scale consists of four hypothetical threatening scenarios (dentist, aeroplane, dismissal, and hostage), each followed by eight coping options. Four options represent a monitoring style of coping (e.g., 'I watch the dentist's movements and listen for the drill', 'I stay alert and keep myself from falling asleep', 'I listen to the engines for unusual noises'), whereas the other four are blunting options. Subjects are asked to indicate on a five-point scale to what extent each option applies to them $(1=$ not at all, $5=$ very much). A total monitoring score can be obtained by summing across the relevant options (range 16-80).

The STAI was used to measure levels of trait anxiety (range 20-80).

The Anxiety Sensitivity Index (ASI; Reiss, Peterson, Gursky \& McNally, 1986) measures subjects' evaluation of bodily sensations and the fear associated with these 
symptoms. The ASI consists of 16 items (e.g., 'I feel frightened when my heart beats fast') which are scored on a five-point scale $(0=$ not applicable to me, $4=$ very much applicable to me). A total score can be calculated by summing scores on the individual items (range 0-64).

The Body Sensations Questionnaire (BSQ; Chambless, Caputo, Bright \& Gallager, 1984) is a concurrent measure of the ASI and also taps fear of bodily sensations. The BSQ-version that was used in the present study lists 14 bodily sensations (e.g., palpitations, dizziness). The subject is asked to indicate the level of fear associated with each sensation $(0=$ not at all frightened by this sensation, $8=$ extremely frightened by this sensation). BSQ total scores vary between 0 and 112 .

The modified version of the Body Sensations Interpretation Questionnaire (BSIQ; Clark et al., 1997) that was used in the current study describes seven bodily sensations (e.g., 'You notice that your heart is beating quickly and pounding'). Each description is followed by three alternative explanations. One explanation is panic-related (e.g., 'There is something wrong with my heart'), the remaining two are neutral (e.g., 'I have been physically active'). Subjects have to rate the extent to which they endorse the explanations for each bodily sensation on nine-point scales $(0=$ not at all likely, $8=$ very much likely). A BSIQ panic score can be calculated by summing belief ratings across panic-related explanations (range 0-56), while a BSIQ neutral score is obtained by summing belief ratings across neutral explanations (range 0-112).

The agoraphobia scale of the Fear Questionnaire (FQ-agoraphobia; Marks \& Mathews, 1979) consists of five items describing situations that are typically avoided by agoraphobic individuals (e.g., 'Traveling alone by bus or train'). Each item has to be scored on a nine-point scale $(0=$ never avoid, $8=$ always avoid $)$. Total FQ agoraphobia scores range between 0 and 40 .

\section{Results and discussion}

Before addressing the main research question of the present study, some remarks about the general statistics are in order. First of all, mean scores on the various instruments were comparable with those of normal subjects in previous studies. Second, all questionnaires were reliable in terms of internal consistency: Cronbach's alphas varied between 0.64 (BSIQ panic) and 0.92 (STAI trait anxiety; see Table 1).

The left columns of Table 2 present Pearson product-moment correlations between monitoring and trait anxiety, on the one hand, and scores on panic measures, on the other hand. As can be seen, trait anxiety was substantially related to most of the panic measures, i.e., fear of bodily sensations (ASI and BSQ), agoraphobia (FQ), and the misinterpretation of bodily sensations (BSIQ panic). Smaller correlations were found between monitoring and fear of bodily sensations (ASI and BSQ) and agoraphobia (FQ). Inspection of the scatterplots revealed that all aforementioned correlations involved linear associations. Interestingly, monitoring was by no means related to the misinterpretation of bodily sensations (BSIQ panic; $r=0.05$ ). Note in passing that neither trait anxiety nor monitoring were associated with BSIQ neutral. 
Table 1

General statistics (mean, standard deviation, and Cronbach's alpha) of the various questionnaires that were used in the present study ${ }^{\mathrm{a}}$

\begin{tabular}{lcc}
\hline & $M(\mathrm{SD})$ & $\alpha$ \\
\hline Monitoring & $56.9(8.2)$ & 0.76 \\
Trait anxiety & $38.4(9.5)$ & 0.92 \\
ASI & $28.7(7.5)$ & 0.84 \\
BSQ & $23.5(15.0)$ & 0.91 \\
FQ agoraphobia & $3.8(5.1)$ & 0.79 \\
BSIQ panic & $11.1(6.5)$ & 0.64 \\
BSIQ neutral & $53.6(13.6)$ & 0.78 \\
\hline
\end{tabular}

${ }^{\mathrm{a}} \mathrm{ASI}=$ Anxiety Sensitivity Index, BSQ $=$ Body Sensations Questionnaire, FQ $=$ Fear Questionnaire, $\mathrm{BSIQ}=$ Bodily Sensations Interpretation Questionnaire.

The correlation between STAI trait anxiety and monitoring was nonsignificant, $r=0.10$, indicating that both measures are largely independent. Computing partial correlations between monitoring and panic measures while correcting for trait anxiety essentially revealed an identical pattern of results, i.e., small correlations between monitoring and fear of bodily sensations and agoraphobia were found, while the correlation between monitoring and the index of catastrophic misinterpretation (BSIQ) failed to reach significance. In the meantime, most associations between trait anxiety and panic measures remained substantial while controlling for monitoring (see the right columns of Table 2).

It should be mentioned that, in the present study, a large number of correlations were computed. In order to control for the inflation of a type I error rate, a Bonferroni correction was applied: $\alpha$ was set to $0.05 / 21$ for the bivariate correlations and to $0.05 / 10$ for the partial correlations. Results showed that only the associations between trait anxiety and (most) panic disorder symptoms measures remained significant. None of the correlations between monitoring and panic measures reached the adjusted significance level.

The current study found some positive associations between a monitoring coping style, on the one hand, and fear of bodily sensations and agoraphobic avoidance, on the other hand. This finding is in keeping with the results of previous studies showing that subjects relying on a high monitoring coping style perceive potentially threatening stimuli and situations as more threatening than subjects relying on a low monitoring coping style (see Baptista et al., 1990; Muris \& Van Zuuren, 1992; Muris \& De Jong, 1993; Muris, De Jong \& Suvrijn, 1995; Schwartz et al., 1995) and, on first sight, seem to provide further support for the Monitoring Process Model (e.g., Miller et al., 1995). However, the observed correlations between monitoring and panic disorder symptoms were rather small. Moreover, in agreement with the study of Baptista et al. (1990), monitoring was not found to be associated with the catastrophic misinterpretation of bodily sensations. Assuming that such misinterpretations are the vehicle behind panic attacks and panic disorder, the present findings do not confirm the notion that monitoring is a risk factor for panic disorder (Miller, 1992). 


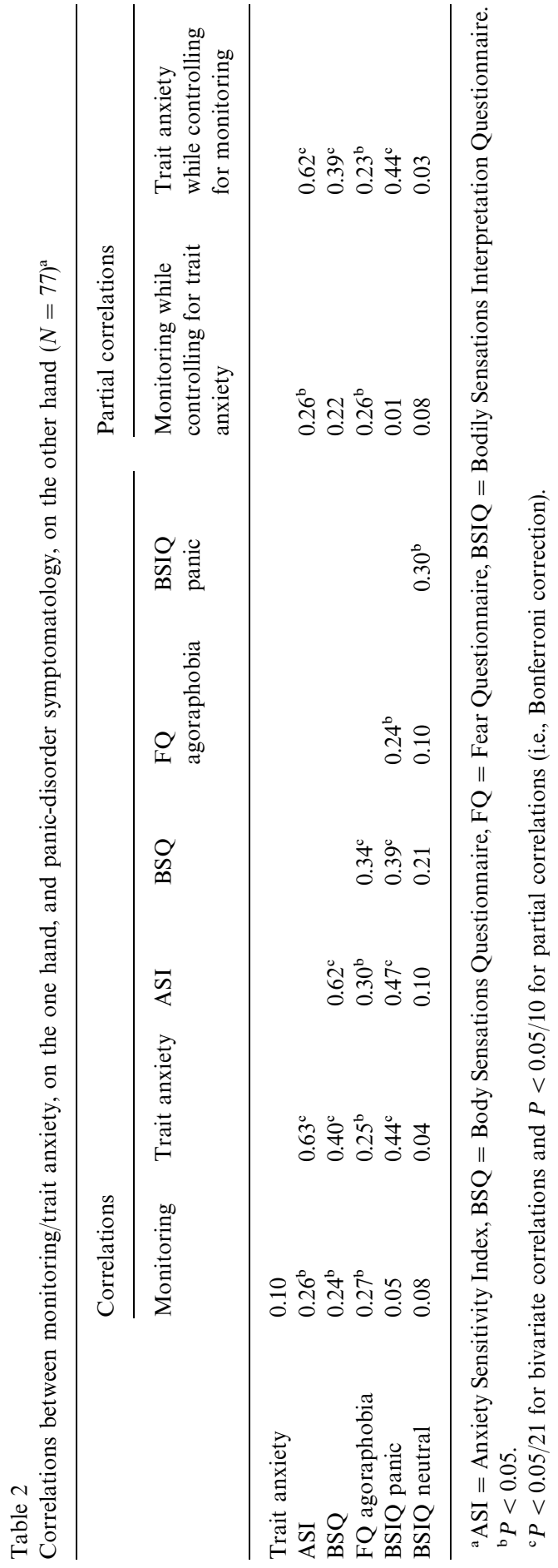


The results do add further weight to the idea that trait anxiety is a vulnerability factor for anxiety disorders such as panic disorder (Eysenck, 1992; Rachman, 1998). Most importantly, trait anxiety was significantly associated with the catastrophic misinterpretation of bodily symptoms, which is according to the cognitive theory of panic (e.g., Clark, 1986) a conditio sine qua non for developing this disorder.

Taken together, the current study found little support for Miller's (1992) speculation that a monitoring coping style is implicated in the etiology of panic. Compared to monitoring, trait anxiety appears to be a more powerful correlate of panic relevant characteristics (i.e., catastrophic misinterpretation of somatic sensations). Note that this conclusion nicely fits with the well-documented finding that high trait anxious individuals report more physiological symptoms than low trait anxious persons. In addition, high trait anxious individuals tend to disambiguate ambiguous stimuli in a threatening way (see, for a review, Eysenck, 1992).

\section{References}

American Psychiatric Association (1994). Diagnostic and statistical manual of mental disorders, (4th ed.) (DSM-IV). Washington: American Psychiatric Association.

Baptista, A., Figueira, M. L., Lima, M. L., \& Matos, F. (1990). Bias in judgement in panic disorder patients. Acta Psyquiátrica Portuguesa, 36, 25-35.

Chambless, D. L., Caputo, G. C., Bright, P., \& Gallagher, R. (1984). Assessment of fear in agoraphobics: The Boby Sensations Questionnaire and the Agoraphobic Cognitions Questionnaire. Journal of Consulting and Clinical Psychology, 52, 1090-1097.

Clark, D. M. (1986). A cognitive approach to panic. Behaviour Research and Therapy, 24, 461-470.

Clark, D. M., Salkovskis, P. M., Öst, L. G., Breitholz, E., Koehler, K. A., Westling, B. E., Jeavons, A., \& Gelder, M. (1997). Misinterpretation of body sensations in panic disorder. Journal of Consulting and Clinical Psychology, 65, 203-213.

Eysenck, M. W. (1992). Anxiety. The cognitive perspective. Hove: Erlbaum.

Krohne, H. W. (1993). Vigilance and cognitive avoidance as concepts in coping research. In H. W. Krohne, Attention and avoidance. Strategies in coping with aversiveness (pp. 19-50). Göttingen: Hogrefe \& Huber.

Marks, I. M., \& Mathews, A. M. (1979). Brief standard self-rating for phobic patients. Behaviour Research and Therapy, 17, 263-267.

McNally, R. J. (1994). Panic disorder, a critical analysis. New York: Guilford Press.

Miller, S. M. (1987). Monitoring and blunting: Validation of a questionnaire to assess styles of information seeking under threat. Journal of Personality and Social Psychology, 52, 345-353.

Miller, S. M. (1992). Monitoring and blunting in the face of threat: Implications for adaptation and health. In L. Montada, S. H. Filipp, \& M. J. Lerner, Life crisis and experiences of loss in adulthood (pp. 255-273). Hillside: Erlbaum.

Miller, S. M., Combs, C., \& Kruus, L. (1993). Tuning in and tuning out: Confronting the effects of confrontation. In H. W. Krohne, Attention and avoidance. Strategies in coping with aversiveness (pp. 51-69). Göttingen: Hogrefe \& Huber.

Miller, S. M., \& Mangan, C. E. (1983). Interacting effects of information and coping style in adapting to gynaecologic stress: Should the doctor tell all?. Journal of Personality and Social Psychology, 45, 223-236.

Miller, S. M., Roussi, P., Caputo, C., \& Kruus, L. (1995). Patterns of children's coping with an aversive dental treatment. Health Psychology, 14, 236-246.

Muris, P. (1994). Monitoring and blunting. Coping styles and strategies in threatening situations. Maastricht: Datawyse.

Muris, P., De Jongh, A., Van Zuuren, F. J., \& Schoenmakers, N. (1996). Monitoring-blunting coping styles and cognitive symptoms of dental fear. European Journal of Psychology, 10, 35-44. 
Muris, P., \& Van Zuuren, F. J. (1992). Monitoring, medical fears, and physical symptoms. British Journal of Clinical Psychology, 31, 360-362.

Muris, P., \& De Jong, P. J. (1993). Monitoring and perception of threat. Personality and Individual Differences, 15, 467-470.

Muris, P., De Jong, P. J., \& Suvrijn, A. (1995). Monitoring, imagery, and perception of threat. Personality and Individual Differences, 18, 749-759.

Rachman, S. J. (1998). Anxiety. Hove: Psychology Press.

Reiss, S., Peterson, R. A., Gursky, D. M., \& McNally, R. J. (1986). Anxiety sensitivity, anxiety frequency, and the prediction of fearfulness. Behaviour Research and Therapy, 24, 1-8.

Schwartz, M. D., Lerman, C., Miller, S. M., Daly, M., \& Masny, A. (1995). Coping disposition, perceived risk, and psychological distress among women at increased risk for ovarian cancer. Health Psychology, 14, 232-235.

Spielberger, C. D. (1983). State-Trait Anxiety Inventory (STAI). Palo Alto: Consulting Psychologists Press. 